\title{
At a crossroads: examining Covid-19's impact on public and digital diplomacy
}

\author{
Ilan Manor ${ }^{1} \cdot$ James Pamment ${ }^{2}$
}

Revised: 17 October 2021 / Accepted: 25 October 2021 / Published online: 13 January 2022

(c) The Author(s), under exclusive licence to Springer Nature Limited 2021

The Covid-19 pandemic was a unique global crisis that has significantly changed social, cultural, and political behaviours. For one, the world is no longer as international: airports and borders have closed, and hurdles such as frequent testing and quarantine have deterred cross-border travel. Additionally, countries reasserted their sovereignty: by seeking to demonstrate their ability to provide good governance, many promoted their own interests against their neighbours. Trust in others became as rare a commodity as toilet paper, at least if the tabloids are to be believed.

Third, people around the world have undergone similar trauma: the loss of close ones, a need to protect the vulnerable, a decline of jobs and industries, fear of losing basic services, as well as social distancing and isolation. The need to feel connection to countries, institutions, colleagues, friends, and loved ones despite physical distance invites a rethink of the role-actual and potential—of public diplomacy as a force for good in international relations.

This Special Issue has taken on a unique format of shortform case studies to bring together leading scholars in a discussion of what Covid-19 means for the present and future of public diplomacy. Across 12 papers, the authors explore Covid-19 and PD involving countries such as Brazil, China, France, Germany, India, Japan, Mexico, Norway, Romania, Russia, Sweden, the UK, and the US among others. They raise conceptual issues impacting on PD such as empathy and belonging, authoritarianism and populism, global protest, reputational security, crisis communication, and narrative battles.

Ilan Manor

manor.ilan@gmail.com

Tel Aviv University, Tel Aviv, Israel

2 Lund University, Lund, Sweden

\section{PD and empathy: engaging the diaspora and beyond}

The first major area focuses on domestic and diaspora public diplomacy. What role does government communication with global diasporas play in PD during crises? Throughout the pandemic, diplomats and diplomatic institutions publicised their consular efforts to repatriate citizens while celebrating consular success stories such as charted repatriation flights. How can cultural and humanistic approaches to PD overcome the raw projection of national interests?

In addressing these questions, R.S. Zaharna outlines a theory of human-centred PD and argues that the pandemic calls for an expansion of PD's toolbox to embrace empathy and perspective-taking. Natalia Grincheva focuses on cultural diplomacy by exploring some of the ways in which UK museums engaged with international audiences during lockdown. Drawing on her research into the Romanian diaspora in the UK, Alina Dolea discusses how PD during Covid-19 and under the shadow of Brexit managed to raise sensitive themes such as emotion and belonging. Finally, Muhammad Ittefaq approaches the question of how the Indian diaspora has been able to participate in the country's public sphere during a period of internet restrictions.

\section{PD as image management: crisis communication during an emerging global security threat}

The second area focuses on the crisis and media management aspects of the pandemic. To what extent can states prevent public exposure to misleading information pertaining to the causes and spread of Covid-19? How can governments effectively manage perceptions of an emerging crisis when their neighbours behave differently? Does the public's exposure to misleading information pose a national security 
threat? If so, what role do diplomats play in such societal conversations?

In addressing these questions, Nick Cull returns to the concept of reputational security and explores four strategies that governments used to manage their international reputations. Corneliu Bjola studies the activities of the German MFA during the early phases of the pandemic in order to show how Heidegger's concept of world disclosure can be applied to digital diplomacy. Jesper Falkheimer and Ketil Raknes outline the crisis communication battle that took place between Norway and Sweden, countries that took markedly different approaches to handling the pandemic. Finally, Nancy Snow assesses Japan's crisis communication in light of the postponement of the 2020 Olympic Games, which were eventually held in 2021.

\section{PD as protest: the diplomacy of underdogs and wolf warriors}

Covid-19 increases an already heightened sense of uncertainty brought about by the paralysis of multilateral institutions and a perpetual state of international crisis. It is in times of uncertainty that the public struggle to make sense of the world around them, which can exacerbate existing tensions between public and governments. On the one hand, this can lead to protests. On the other, it can lead to governments feeling misunderstood by global public. How are these countervailing trends expressed in PD?

César Jiménez-Martínez explores the ways in which the pandemic deepened and aggravated existing social tensions, generating dozens of protests with transnational aspects. Noting the high level of international media coverage these protests received, the author argues for greater attention to be placed on these manifestations of citizen diplomacy in PD scholarship. Zhao Alexandre Huang addresses China's efforts to push back on negative perceptions of its role in the origins of the pandemic. Known as Wolf Warrior diplomacy, the author examines the Chinese embassy's narrative strategy in French social media posts, noting an assertive stance in denying criticism towards its model for handling the pandemic.

\section{PD and populism: crafting cults of nationalism and celebrity}

During times of crisis and uncertainty, the familiar performs a vital role. On the one hand, strong leaders can fulfil this function by offering stability and leadership. Other kind of leaders, in the form of celebrities, can perform a similar role. On the other hand, historical references can also provide an interesting strategy, such as through references to overcoming previous crises. Has Covid-19 increased the strength of populist movements, given that populists offer sense making as a nation's glorious past is summoned to the present? How may this be developed into public diplomacy resources?

Annika Bergman Rosamond and Elsa Hedling consider Swedish Chief State Epidemiologist Anders Tegnell as a kind of celebrity diplomat, who developed into the focal point for international coverage of Sweden's exceptionalist approach to handling the pandemic. Finally, Ilan Manor and James Pamment explore the use of nostalgic tropes in Russia's digital diplomacy about the pandemic, which tie into broader domestic and regional historical revisionism efforts.

Though this Forum focuses on the Covid-19 pandemic, the various contributions also highlight issues that are of central importance to the study and practice of public diplomacy. First, contributors re-examine who constitute the 'public' in public diplomacy. Is PD still limited to foreign publics and diasporas, or do governments and diplomats now also target their national citizenry? This is most evident when diplomats share consular success stories. Second, do local and global feelings of uncertainty limit or constrain the practice of PD? Are the audiences of public diplomacy less likely to engage with government communications given a lack of trust in national and global governance institutions? If so, how can diplomats restore trust in such institutions?

Third, what role do national images play in contemporary PD? Do governmental blunders in managing a pandemic send global ripple effects which negatively impact a nation's standing and its ability to manage change in the international system? Conversely, do national success stories and effective crisis management pave the way for greater influence on the global stage? Finally, what role does the past play in today's PD? Is the past used as a template to understand the present, as a tool to reduce feelings of anxiety by assuring public that nations have survived past challenges, or is the past used to re-imagine the present and influence public perception of present-day challenges?

While Covid-19 brings these issues to the fore, these issues are all central to the study of PD in the second decade of the twenty-first century. As such, this Forum hopes to facilitate new discussions among PD scholars and to identify relevant areas of future research.

Acknowledgements James Pamment is grateful for funding from the Marianne and Marcus Wallenberg Foundation for the Project Digital Diplomacy in a Turbulent World.

Publisher's Note Springer Nature remains neutral with regard to jurisdictional claims in published maps and institutional affiliations. 
Ilan Manor is a digital diplomacy scholar at Tel Aviv University. Manor is also a visiting fellow at the USC Center on Public Diplomacy where he is examining diplomat's use of visuals on social media. Manor received his PhD from the University of Oxford where he examined diplomats' use of social media during times of crises. Manor is the Vice Chair of the Public Diplomacy Interest Group in the International Communication Association and a guest lecturer at the University of Oxford. Manor's upcoming co-edited book, The Digital Diplomacy Handbook, will be published by Oxford University Press in 2022.
James Pamment is a Senior Lecturer at Lund University's Department of Strategic Communications. Pamment was a postdoctoral fellow at the Department of International Development at Oxford University, and at the Moody College of Communication at the University of Texas at Austin. He was also a non-residential research fellow at the University of Southern California Center on Public Diplomacy between 2013 and 2015 and is the editor of Place Branding and Public Diplomacy. 